\title{
Lateral supracerebellar infratentorial approach for microsurgical resection of large midline pineal region tumors: techniques to expand the operative corridor
}

\author{
Charles Kulwin, MD, ${ }^{1}$ Ken Matsushima, MD, ${ }^{2}$ Mahdi Malekpour, MD, ${ }^{1}$ and \\ Aaron A. Cohen-Gadol, MD, MSc ${ }^{1}$ \\ ${ }^{1}$ Goodman Campbell Brain and Spine, Indiana University Department of Neurological Surgery, Indianapolis, Indiana; and \\ 2Department of Neurological Surgery, University of Florida, Gainesville, Florida
}

\begin{abstract}
Pineal region tumors pose certain challenges in regard to their resection: a deep surgical field, associated critical surrounding neurovascular structures, and narrow operative working corridor due to obstruction by the apex of the culmen. The authors describe a lateral supracerebellar infratentorial approach that was successfully used in the treatment of 10 large $(>3 \mathrm{~cm})$ midline pineal region tumors. The patients were placed in a modified lateral decubitus position. A small lateral suboccipital craniotomy exposed the transverse sinus. Tentorial retraction sutures were used to gently rotate and elevate the transverse sinus to expand the lateral supracerebellar operative corridor. This approach placed only unilateral normal structures at risk and minimized vermian venous sacrifice. The surgeon achieved generous exposure of the caudal midline mesencephalon through a "cross-court" oblique trajectory, while avoiding excessive retraction on the culmen. All patients underwent the lateral approach with no approach-related complication. The final pathological diagnoses were consistent with meningioma in 3 cases, pilocytic astrocytoma in 3 cases, intermediate grade pineal region tumor in 2 cases, and pineoblastoma in 2 cases. The entire extent of these tumors was readily reachable through the lateral supracerebellar route. Gross-total resection was achieved in $8(80 \%)$ of the 10 cases; in 2 cases (20\%) near-total resection was performed due to adherence of these tumors to deep diencephalic veins.

Large midline pineal region tumors can be removed through a unilateral paramedian suboccipital craniotomy. This approach is simple, may spare some of the midline vermian bridging veins, and may be potentially less invasive and more efficient.
\end{abstract}

http://thejns.org/doi/abs/10.3171/2015.2.JNS142088

KEY WORDS pineal region tumors; suboccipital craniotomy; paramedian approach; cerebellar retraction; surgical technique

$\mathrm{T}$ HE bilateral suboccipital midline approach to the pineal region was initially described in the early 20th century ${ }^{6}$ and has progressively been refined based on microsurgical techniques. ${ }^{11}$ Subsequent operative and cadaveric studies have led to descriptions of a continuum of supracerebellar infratentorial (SCIT) approaches to the posterior and lateral tentorial incisural space as one moves farther away from the midline. ${ }^{15,16}$ These approaches have coalesced into 3 named SCIT routes: the classic midline approach, the lateral or paramedian approach, and the farlateral approach. ${ }^{9}$ Other approaches to the region include the transtentorial supracerebellar, ${ }^{13,18}$ occipital transtentorial, ${ }^{7}$ and transcallosal interhemispheric variations. ${ }^{3}$
Most neurosurgeons employ the midline supracerebellar route for exposing large midline pineal region tumors due to their familiarity with this technique and a need to avoid deep venous structures that are often displaced superiorly and dorsally. It is intuitive that a midline lesion would favor a midline approach. Certain limitations of the median approach are unavoidable, including a long, steep working angle using either a sitting or Concorde position ${ }^{4}$ as well as limited lateral or inferior visualization caused by the angle of the tentorium and the obstructive apex of the culmen, respectively.

A paramedian supracerebellar approach offers the possibility of offsetting some of these disadvantages. The

ABBREVIATION SCIT = supracerebellar infratentorial. 
trajectory over the lateral cerebellum or the quadrangular lobule is more direct and less steep than the one over the apex of the culmen. Similarly, a paramedian approach avoids the median supracerebellar region where bridging veins are most numerous. ${ }^{5}$ Wide arachnoid dissection allows the lateral, more inferiorly situated, cerebellar hemisphere to fall away from the tentorium and posterior mesencephalon, thereby avoiding the need for aggressive retraction on the culmen.

Finally, the unilateral suboccipital craniotomy protects the torcula, the contralateral transverse sinus, and the cerebellum, therefore minimizing morbidity. Although this paramedian approach was previously noted to provide an inadequate operative view for resection of large pineal region tumors, ${ }^{3}$ we initially explored and ultimately used this corridor for excision of such large tumors $(>3 \mathrm{~cm})$. To assist with the understanding and application of the paramedian approach to these masses, herein we describe the technical nuances of this approach, supplemented by cadaveric dissections, illustrations, intraoperative images, and 2 videos.

\section{Operative Technique}

After induction of anesthesia, a lumbar drain may be placed, if deemed safe, to assist with brain relaxation. The patient is placed in the right lateral decubitus position. The left-sided suboccipital craniotomy protects the torcula and the often more dominant right-sided veins and dural sinuses, including the transverse sinus. In the event of a left-dominant venous system, an approach from the contralateral side may be considered. We did not study the dominance of the transverse sinus preoperatively in our patients, all of whom underwent a left-sided approach. A skull clamp is used with the patient's neck flexed and head turned slightly $\left(15^{\circ}-20^{\circ}\right)$ toward the floor (Fig. 1). The ipsilateral shoulder is allowed to fall forward and is taped away from the surgeon's working zone. Intraoperative neuronavigation is used to identify the exact location of the midline as well as the transverse and sigmoid sinuses. A paramedian vertical linear incision is made halfway between the inion and the transverse-sigmoid junction approximated by the posterior-superior edge of the mastoid groove. This incision extends one-third above and two-thirds below the transverse sinus and is about 7-8 cm in length. The suboccipital muscles are elevated from the bone and a single myocutaneous layer is retracted.

A single bur hole is made using neuronavigation at the inferior edge of the transverse sinus, approximately $2 \mathrm{~cm}$ lateral to the midline and torcula. Next, an infratentorial craniotomy flap is elevated, including removal of bone superiorly until the width of the transverse sinus was exposed. All our patients underwent identical craniotomies. The entire width of the transverse sinus is exposed to allow room for later rostral mobilization of this venous sinus. The single bur hole allows elevation of a 1-piece bone flap over the infratentorial dura and transverse sinus safely after the wall of the sinus is mobilized away from the skull; CSF drainage through the lumbar drain assists with this dural mobilization. The dura is opened as a single curved flap based on the sinus. Two retraction sutures are placed along the posterior aspect of the tentorium to mobilize

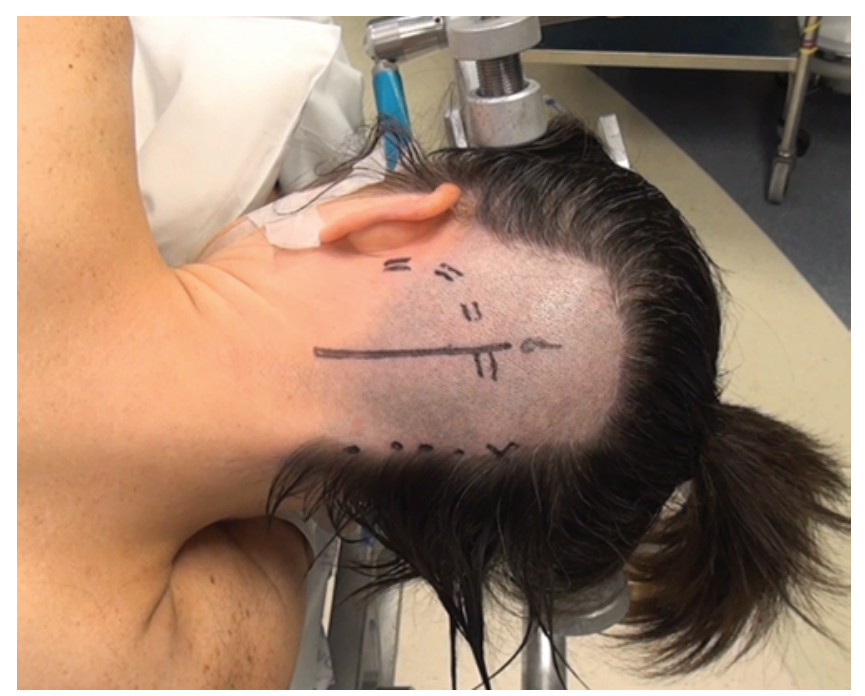

FIG. 1. The patient is placed in the right lateral decubitus position. The left-sided suboccipital craniotomy protects the torcula and the dominant right-sided veins and dural sinuses, including the transverse sinus (left transverse and sigmoid sinuses are marked with dashed lines). A skull clamp is used with the patient's neck flexed and head turned slightly $\left(15^{\circ}\right)$ toward the floor. Figure is available in color online only.

and gently rotate the transverse sinus superiorly to expand the operative space through the supracerebellar corridor (Fig. 2). ${ }^{10}$ Gradual CSF release through the lumbar drain allows gentle caudal mobilization of the lateral cerebellar hemisphere. The tentorial surface of the cerebellum is highest along its anteromedial apex and slopes down laterally. Therefore, the lateral paramedian operative corridor provides a more inferior trajectory to the posterior midline and posterolateral mesencephalon, as compared with the midline trajectory, to access the inferior extension of large pineal region tumors (Fig. 3).

Bridging arachnoid adhesions between the lateral cerebellum and inferior tentorial surface are dissected sharply. A lateral hemispheric bridging vein is at times coagulated and sacrificed. Large median bridging veins are left intact. The arachnoid is opened ventrally to enter bilateral ambient and quadrigeminal cisterns and then extended medially and laterally until the midline operative corridor is established. Early during dissection, a small portion of the trochlear nerve and superior cerebellar artery branches are identified along the very lateral aspects of the operative route to avoid their injury; their arachnoid membranes are left intact. Once adequate medial arachnoid dissection is completed, the large midline lesion along the incisura is well visualized from an oblique trajectory. Neuronavigation is used to confirm the extent of the lesion. The critical diencephalic venous structures are displaced dorsally and medially. Dynamic retraction of the cerebellum, using the suction apparatus, allows exposure and resection of the inferior extent of the tumor without the use of fixed retractors. The suction apparatus allows a more controlled expanded view of the working zone at the exact location of the dissection, while the wide blade of the retractor may at times compromise the deep exposure due to its less flexible vector of retraction. Generous exposure of the contra- 

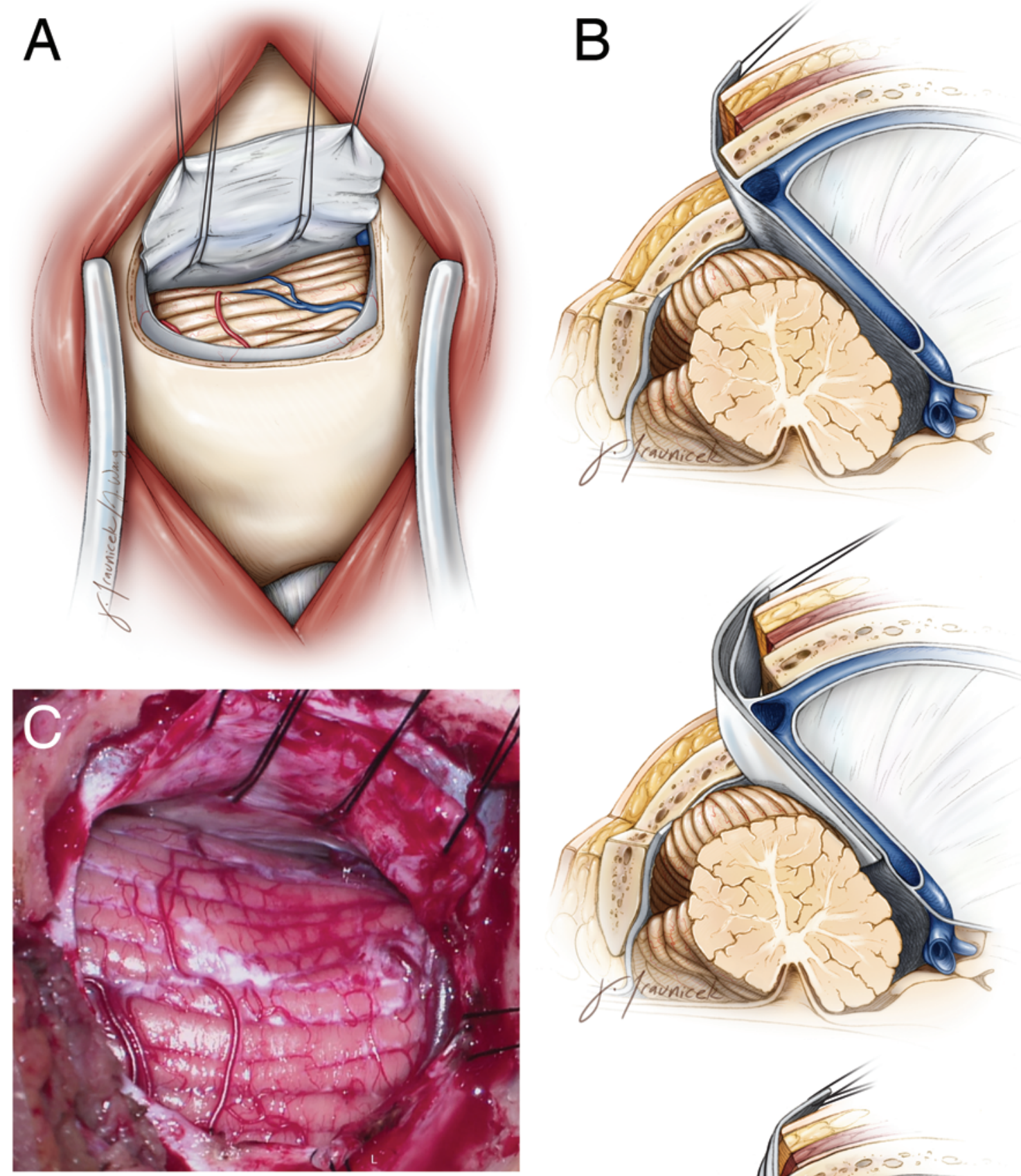

FIG. 2. Two retraction sutures are placed along the posterior aspect of the tentorium to mobilize and gently rotate the left transverse sinus superiorly $(\mathrm{A})$ and to expand the operative space through the supracerebellar corridor (B). In Panel B, the upper image demonstrates traditional extent of craniotomy without any bony removal over the sinus, the middle image demonstrates extended approach with exposure of the transverse sinus, and the lower image defines the expansion of the supracerebellar operative corridor by mobilization of the transverse sinus. The operative corridor at the end of resection is demonstrated in C. Fixed retractors are not used. From The Neurosurgical Atlas by Aaron A. Cohen-Gadol. Used with permission. Figure is available in color online only.

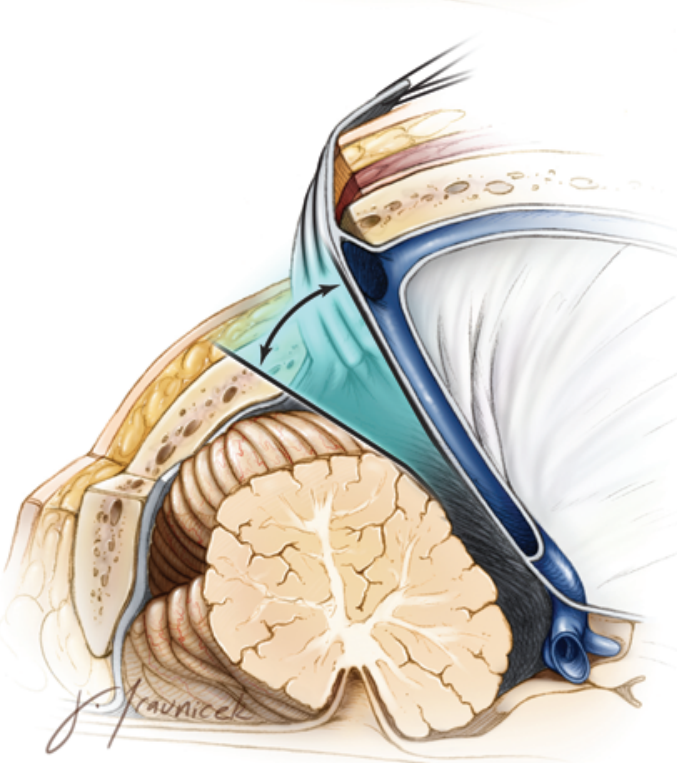




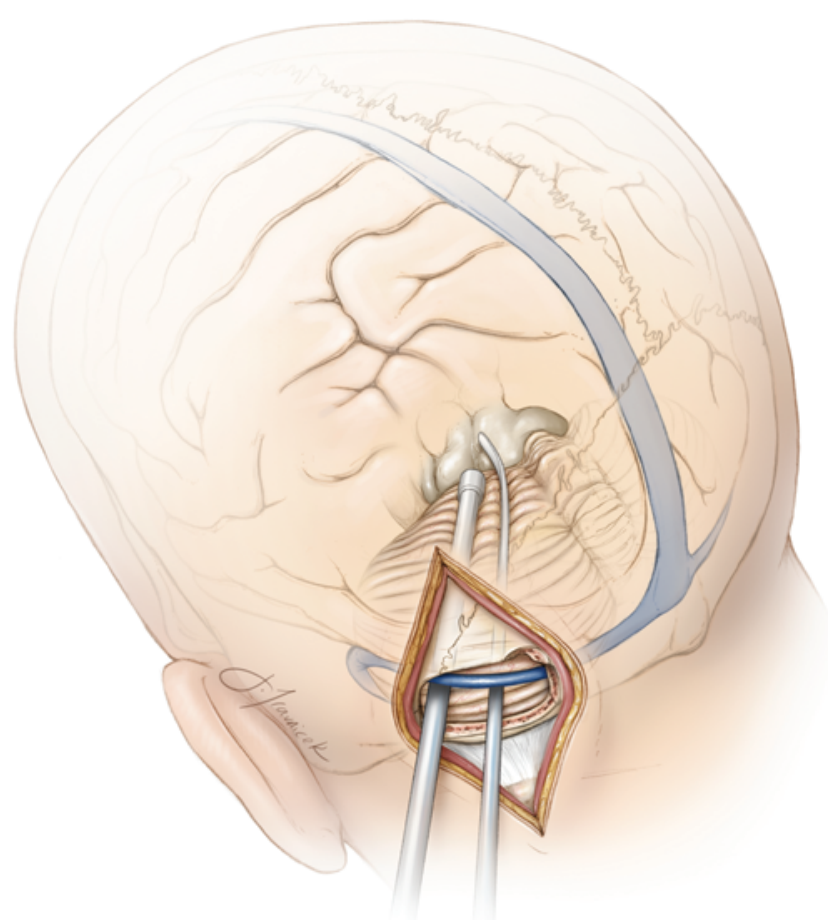

FIG. 3. The lateral paramedian supracerebellar operative corridor provides a more inferior and oblique trajectory to the posterior midline and posterolateral mesencephalon as compared with the midline trajectory to access the inferior extension of large pineal region tumors. From The Neurosurgical Atlas by Aaron A. Cohen-Gadol. Used with permission. Figure is available in color online only.

lateral tectum is readily available through this unilateral working channel and near the falx cerebelli. This oblique view allows the approach to be tailored to the venous anatomy rather than the lateral extent of the lesion, allowing excellent exposure of the contralateral extent of the tumor.

\section{Results}

Our patients included 4 women and 6 men, with an average age of 36 years (range 32-51 years). All patients underwent the above-mentioned left lateral paramedian approach with no approach-related complication. The slight extension of the tumor off midline to either side did not dictate the side of surgery; all patients underwent a leftsided craniotomy. There were 3 meningiomas, 3 pilocytic astrocytomas, 2 intermediate grade pineal region tumors, and 2 pineoblastomas. In all cases, the entire extent of these tumors was readily reachable through the lateral supracerebellar corridor.

Two patients underwent near-total resection of their tumors (1 pilocytic and 1 pineoblastoma) due to adherence of these tumors to the deep diencephalic veins, including the galenic venous system. Gross-total resection was confirmed in the other 8 patients $(80 \%)$ on postoperative MRI. In 6 patients, 1 hemispheric cerebellar bridging vein was sacrificed, while the numerous midline vermian veins were left intact in all patients. No evidence of venous sinus thrombosis was present in any patient's postoperative MRI. In terms of approach-related complications, there was no instance of venous or arterial infarction, although some evidence of temporary mild asymptomatic ipsilateral superior lateral cerebellar edema was noted on the immediate postoperative CT scans in 3 patients. These findings all resolved on 3-month follow-up MRI. There was no instance of new fourth cranial nerve palsy.

\section{Illustrative Cases Case 1}

A 32-year-old woman presented with intractable headaches. MRI revealed a large $(4-\mathrm{cm})$ pineal region mass associated with mild hydrocephalus (Fig. 4). Resection through a lateral supracerebellar approach was completed. Due to extension of the inferior pole of the tumor to the level of the superior medullary velum, a midline approach would have required excessive retraction of the culmen and sacrifice of all midline vermian bridging veins. The tumor, a pineoblastoma, was very adherent to the tectum, and a small amount of tumor was left attached to the galenic venous system to protect its integrity. Postoperatively, the patient suffered from temporary Parinaud's syndrome. MRI revealed a near-total resection of the mass without any complicating features (Fig. 5). The oblique operative trajectory of the lateral supracerebellar route allowed exposure of both lateral extensions of this very adherent tumor to complete resection. Please see Video 1 for the details of this procedure.

VIDEO 1. Video clip from intraoperative recording summarizing the important surgical maneuvers related to Case 1. From The Neurosurgical Atlas by Aaron A. Cohen-Gadol. Used with permission. Click here to view with Media Player. Click here to view with Quicktime.

\section{Case 2}

A 46-year-old woman presented with progressive headaches. She had been diagnosed with a "tectal glioma" 20 years prior and had undergone ventriculoperitoneal shunting for hydrocephalus at that time. The referring neurosurgeon noted significant enlargement of the tumor (3.1 $\mathrm{cm}$ ) (Fig. 6). We performed a left paramedian suboccipital craniotomy and microsurgical resection of her midline posterior mesencephalic pilocytic astrocytoma. This operative corridor allowed generous exposure of the intraaxial tumor with no operative "blind spots." Gross-total resection was possible (Fig. 7). She suffered from postoperative temporary bilateral ptosis with no other evidence of oculomotor palsy. Please see Video 2 for the details of this procedure.

VIDEO 2. Video clip from intraoperative recording illustrating operative findings of Case 2. From The Neurosurgical Atlas by Aaron A.

Cohen-Gadol. Used with permission. Click here to view with Media

Player. Click here to view with Quicktime.

\section{Discussion}

Decades after the first description of the midline pineal approaches, Yaşargil ${ }^{17}$ proposed a paramedian supracerebellar corridor to reach the more laterally located lesions near the incisural space, including the distal superior cerebellar artery aneurysms. In 1990, Van den Bergh ${ }^{15}$ briefly 

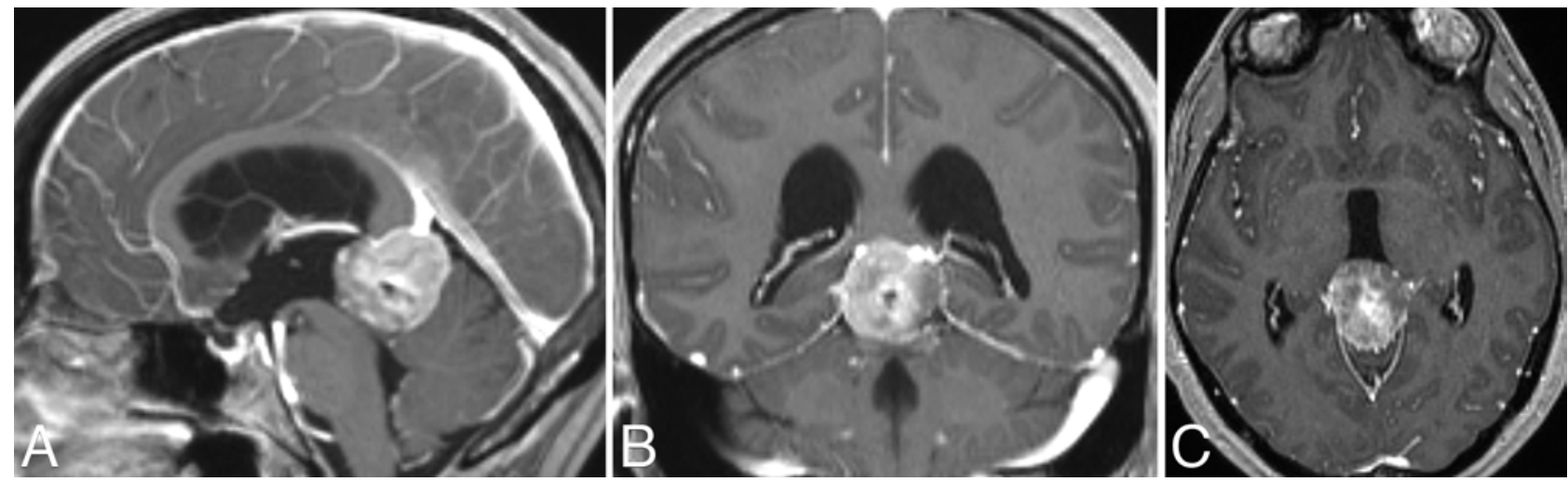

FIG. 4. Preoperative sagittal (A), coronal (B), and axial (C) T1-weighted contrast-enhanced MR images demonstrate a large (4-cm) pineal region pineoblastoma associated with mild hydrocephalus.

noted this paramedian approach for resection of small midline pineal region tumors using 4 cadaveric specimens and his experience with 2 operations. He believed that this route offered several advantages over a midline approach: a shorter working length, decreased cerebellar retraction and minimized risk of venous injury, improved operative ergonomics, and better tumor visualization. Van den Bergh discussed the feasibility of using this technique in only 2 patients. Our current study describes the experience with 10 consecutive patients harboring large pineal region tumors $(>3 \mathrm{~cm})$ who underwent resection using the paramedian suboccipital craniotomy. In addition to the advantages mentioned above, we believe that the unilateral approach is potentially less invasive and more efficient and places fewer normal structures at risk.

Technically, the pineal region is a difficult space to reach and work through because of the limited operative working angle and space. The lack of consensus regarding the preferred approach to the region suggests the shortcomings of the numerous available corridors; indeed, approaches from nearly every possible angle have been described-supra-, infra-, and transtentorial. For most lesions, especially smaller or intrinsic ones, the exact location of the lesion and the anatomical relationships of the surrounding neurovascular structures determine the selected approach. ${ }^{1}$

In the case of larger tumors, however, the advantages of a paramedian supracerebellar approach are more evident, even with the associated longer operative times. Most importantly, through the paramedian approach, the more caudal extension of the larger tumor to the level of the superior medullary velum is readily reached over the inferior slope of the lateral or "wing" of the cerebellum. This extension of the tumor is not easily reached using the midline approach around the culmen, because the apex of the culmen obstructs the operative view (Fig. 8). The paramedian approach therefore prevents the significant downward retraction of the culmen that is required during the midline approach for large tumors. The former route allows a wide arachnoid dissection, which, combined with gravity and CSF drainage, minimizes the need for a fixed retractor. In addition, to provide an adequate operative view for large tumors, the median route requires sacrifice of almost all vermian bridging veins and usually a number of hemispheric veins ${ }^{15}$ (Fig. 9). Although it is often described as benign, there are an increasing number of descriptions of venous infarction with this form of venous sacrifice. ${ }^{2}$ Finally, since operative times increase with dissection of larger tumors, the extent of tissue ischemia and trauma caused by fixed brain retraction also increases. Importantly, this phenomenon is especially compounded by significant venous sacrifice, leading to cerebellar swelling.

We did not use cadaveric specimens to objectively assess the extent of expansion of the operative corridor us-
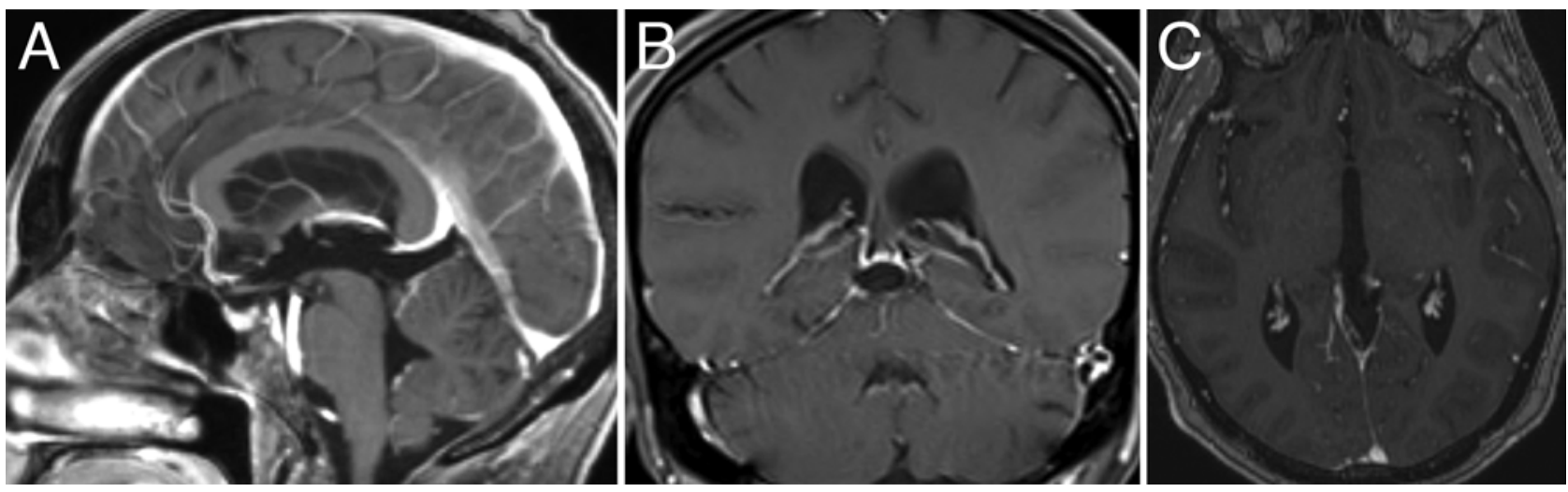

FIG. 5. Postoperative sagittal (A), coronal (B), and axial (C) T1-weighted contrast-enhanced MR images disclose symmetric neartotal resection of the mass with no complicating feature. 

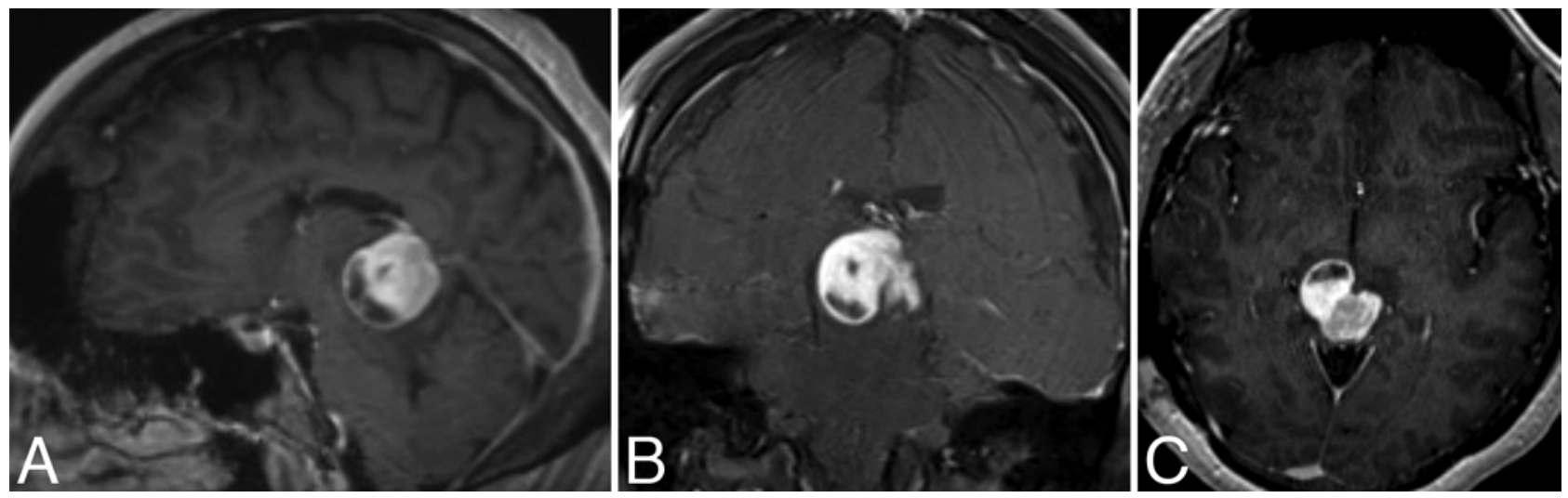

FIG. 6. Preoperative sagittal (A), coronal (B), and axial (C) contrast-enhanced MR images reveal a 3.1-cm midline pineal region pilocytic astrocytoma.
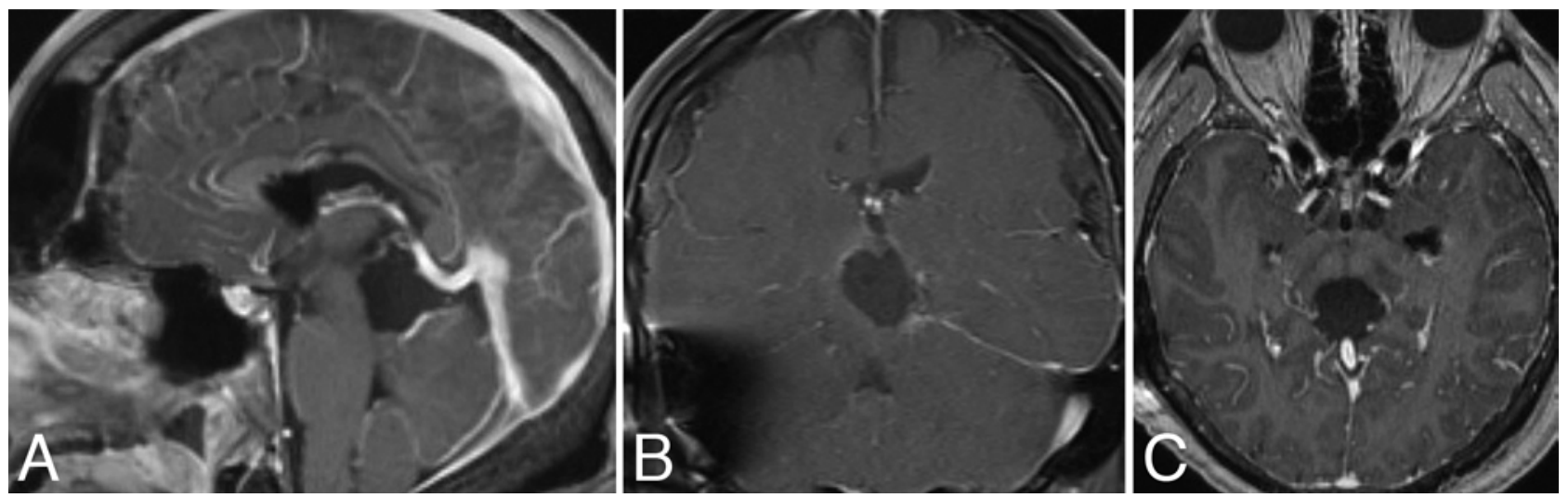

FIG. 7. Postoperative sagittal (A), coronal (B), and axial (C) contrast-enhanced MR images confirm gross-total removal of the tumor.
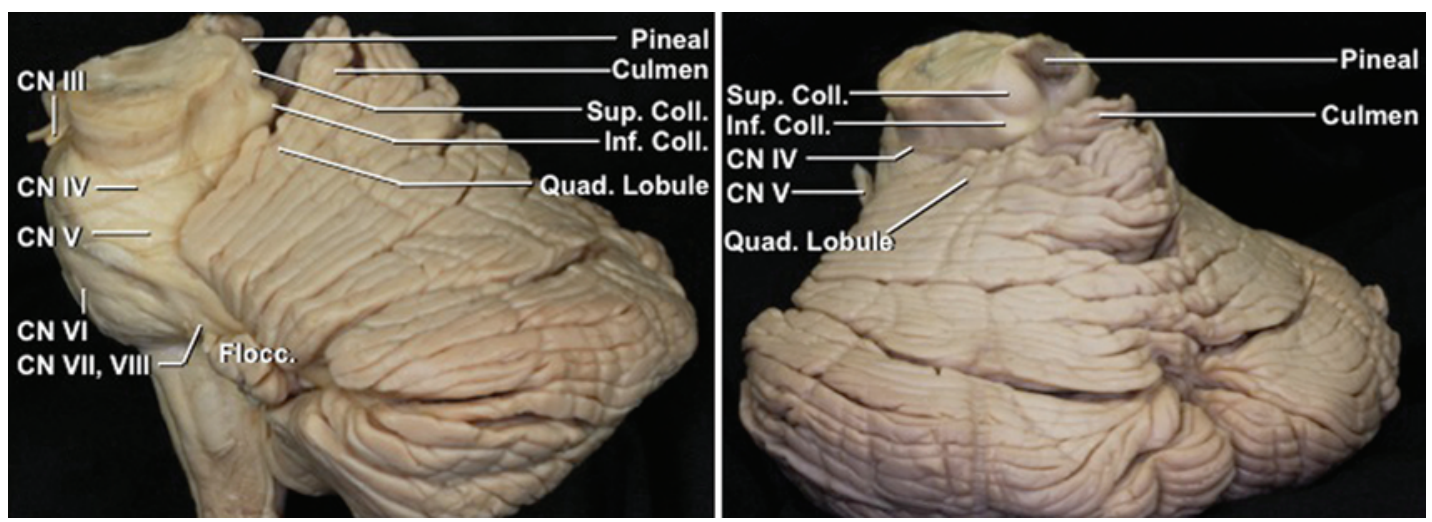

FIG. 8. The pineal region is hidden by the culmen when approached through the traditional midline supracerebellar infratentorial approach (lateral view, left). The paramedian supracerebellar infratentorial approach allows exposure of the pineal region over the more inferiorly situated quadrangular lobule (posterolateral view, right). $\mathrm{CN}=$ cranial nerve; Flocc. = flocculus; Inf. Coll. = inferior colliculus; Quad. = quadrangular; Sup. Coll. = superior colliculus. Figure is available in color online only. 

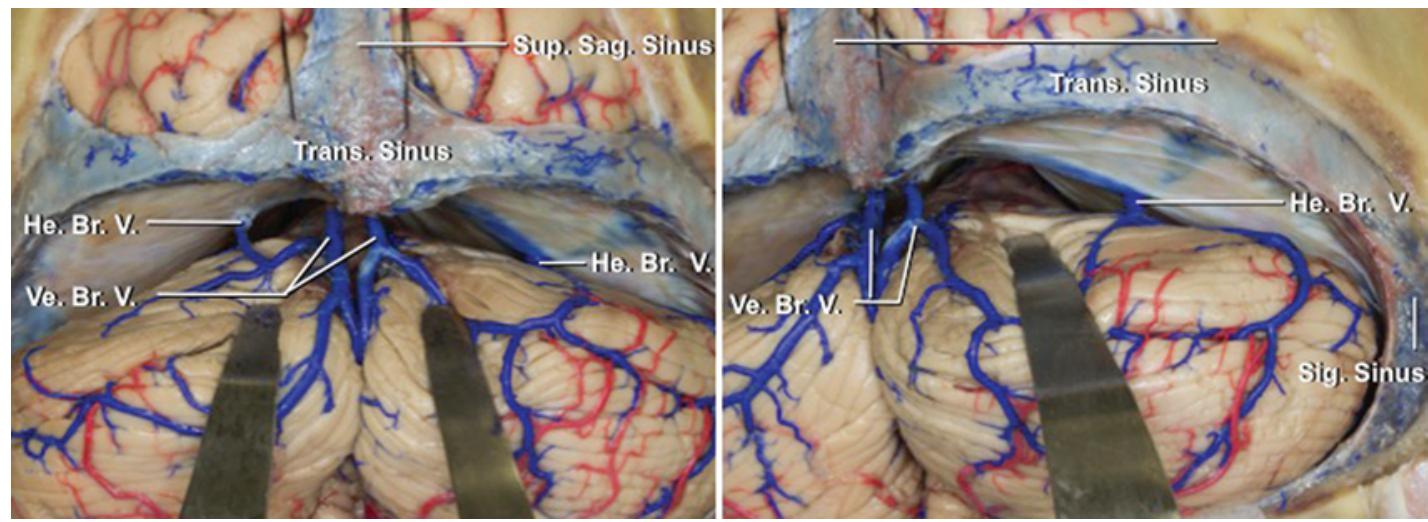

FIG. 9. The vermian and hemispheric bridging veins can be identified (posterior view, left). The paramedian supracerebellar infratentorial approach can minimize vermian venous sacrifice (posterolateral view, right). He. Br. V. = hemispheric bridging vein; Sig. = sigmoid; Sup. Sag. = superior sagittal; Trans. = transverse; Ve. Br. V. = vermian bridging vein. Figure is available in color online only.

ing the paramedian approach because our initial efforts to measure this value in cadavers were deemed ineffective due to the significant stiffness of their cerebelli. We believe that the advantages of the paramedian over a midline suboccipital craniotomy are similar to those of a frontolateral or pterional craniotomy over bifrontal craniotomy for resection of large olfactory groove meningiomas as described by Nakamura et al. ${ }^{8}$

In 1998, a study of supracerebellar venous anatomy by Ueyama et al..$^{14}$ concluded that a median approach requires division of all vermian bridging veins and at least 1 hemispheric vein, whereas a paramedian approach spares the vermian vessels. ${ }^{14}$ Their conclusion was based on the finding that the hemispheric bridging veins are most frequently situated along the intermediate third (59.0\%) and most infrequently in the lateral third $(18.0 \%)$. Kodera et al. ${ }^{5}$ noted that sacrifice of the vermian bridging veins can lead to basal vein thrombosis and that vermian vein sacrifice combined with hemispheric vein division may lead to severe vasogenic swelling. In part, this may be because of the significant collateral connections that exist between hemispheric bridging veins and midline vermian veins. ${ }^{14}$
In sparing the midline venous structures, venous outflow from the superior hemispheric surface is preserved, and hemispheric venous sacrifice may thus be more readily tolerated.

The tentorial surface of the cerebellum is highest along its anteromedial apex and slopes laterally. Therefore, the operative view over the more laterally located quadrangular lobe provides a more inferior trajectory to the posterior midline (superior medullary velum) and posterolateral mesencephalon (Fig. 10). The "cross-court" view provided through the paramedian route facilitates excellent visualization of the contralateral extension of the tumor away from the midline but could potentially compromise access to the ipsilateral anterolateral tumor. Intraoperative endoscopy, well described for supracerebellar pineal region surgery, ${ }^{12}$ could be used as an adjunct to inspect this potential blind spot, and will be explored in our future cases if necessary. However, we have not noticed this area to be problematic for operative access during resection of large tumors (see Case 1 above). The operative working depth for the contralateral reach is long and technically challenging during retractorless surgery.
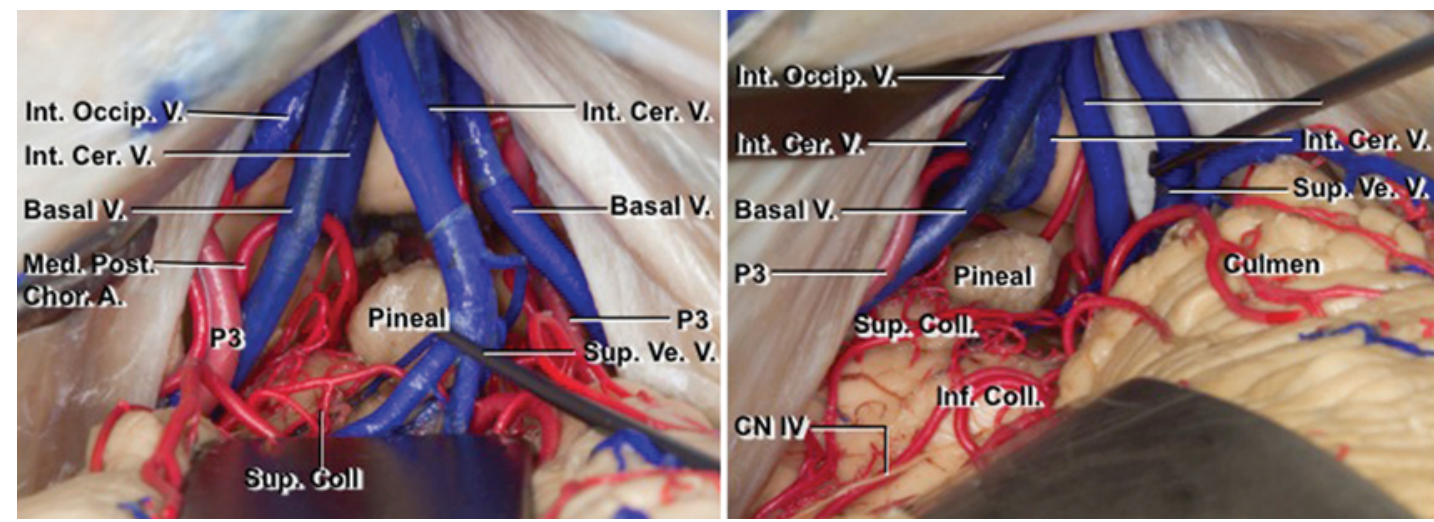

FIG. 10. The midline supracerebellar infratentorial approach can expose the pineal region with retraction of the culmen and the sacrifice of the superior vermian veins (posterior view, left). The paramedian supracerebellar infratentorial approach can reach the superior and inferior colliculi with adequate visualization of the contralateral basal vein (posterolateral view, right). Basal $\mathrm{V} .=$ basal vein; Int. Cer. V. = internal cerebral vein; Int. Occip. V. = internal occipital vein; Med. Post. Chor. A. = medial posterior choroidal artery; Sup. Ve. V. = superior bridging vein. Figure is available in color online only. 


\section{Conclusions}

A paramedian supracerebellar approach may offer certain advantages over the traditional median supracerebellar corridor. These advantages include improved visualization and operative angles for resection of the caudal extension of the tumor while offering a less invasive route and minimizing retraction injury. This approach may be considered for resection of large pineal region tumors.

\section{References}

1. de Oliveira JG, Lekovic GP, Safavi-Abbasi S, Reis CV, Hanel RA, Porter RW, et al: Supracerebellar infratentorial approach to cavernous malformations of the brainstem: surgical variants and clinical experience with 45 patients. Neurosurgery 66:389-399, 2010

2. Jakola AS, Bartek J Jr, Mathiesen T: Venous complications in supracerebellar infratentorial approach. Acta Neurochir (Wien) 155:477-478, 2013

3. Jia W, Ma Z, Liu IY, Zhang Y, Jia G, Wan W: Transcallosal interforniceal approach to pineal region tumors in 150 children. J Neurosurg Pediatr 7:98-103, 2011

4. Kobayashi S, Sugita K, Tanaka Y, Kyoshima K: Infratentorial approach to the pineal region in the prone position: Concorde position. Technical note. J Neurosurg 58:141-143, 1983

5. Kodera T, Bozinov O, Sürücü O, Ulrich NH, Burkhardt JK, Bertalanffy H: Neurosurgical venous considerations for tumors of the pineal region resected using the infratentorial supracerebellar approach. J Clin Neurosci 18:1481-1485, 2011

6. Krause F: Operative Freilengung der Vierhügel, nebst Beobachtungen über Hirndruck und Dekompression. Zentralbl Chir 53:2812-2819, 1926

7. Moshel YA, Parker EC, Kelly PJ: Occipital transtentorial approach to the precentral cerebellar fissure and posterior incisural space. Neurosurgery 65:554-564, 2009

8. Nakamura M, Struck M, Roser F, Vorkapic P, Samii M: Olfactory groove meningiomas: clinical outcome and recurrence rates after tumor removal through the frontolateral and bifrontal approach. Neurosurgery 60:844-852, 2007

9. Ogata N, Yonekawa Y: Paramedian supracerebellar approach to the upper brain stem and peduncular lesions. Neurosurgery 40:101-105, 1997

10. Rey-Dios R, Cohen-Gadol AA: A surgical technique to expand the operative corridor for supracerebellar infratentorial approaches: technical note. Acta Neurochir (Wien) 155:1895-1900, 2013

11. Stein BM: The infratentorial supracerebellar approach to pineal lesions. J Neurosurg 35:197-202, 1971

12. Thaher F, Kurucz P, Fuellbier L, Bittl M, Hopf NJ: Endoscopic surgery for tumors of the pineal region via a paramedian infratentorial supracerebellar keyhole approach (PISKA). Neurosurg Rev 37:677-684, 2014

13. Uchiyama N, Hasegawa M, Kita D, Yamashita J: Paramedian supracerebellar transtentorial approach for a medial tentorial meningioma with supratentorial extension: technical case report. Neurosurgery 49:1470-1474, 2001

14. Ueyama T, Al-Mefty O, Tamaki N: Bridging veins on the tentorial surface of the cerebellum: a microsurgical anatomic study and operative considerations. Neurosurgery 43:11371145,1998

15. Van den Bergh R: Lateral-paramedian infratentorial approach in lateral decubitus for pineal tumours. Clin Neurol Neurosurg 92:311-316, 1990

16. Vishteh AG, David CA, Marciano FF, Coscarella E, Spetzler RF: Extreme lateral supracerebellar infratentorial approach to the posterolateral mesencephalon: technique and clinical experience. Neurosurgery 46:384-389, 2000

17. Yaşargil MG: Microneurosurgery. New York: Thieme, 1987, Vol 1

18. Yonekawa Y, Imhof HG, Taub E, Curcic M, Kaku Y, Roth P, et al: Supracerebellar transtentorial approach to posterior temporomedial structures. J Neurosurg 94:339-345, 2001

\section{Disclosure}

The authors report no conflict of interest concerning the materials or methods used in this study or the findings specified in this paper.

\section{Author Contributions}

Conception and design: all authors. Acquisition of data: all authors. Analysis and interpretation of data: all authors. Drafting the article: all authors. Critically revising the article: all authors. Reviewed submitted version of manuscript: all authors. Approved the final version of the manuscript on behalf of all authors: Cohen-Gadol. Study supervision: Cohen-Gadol.

\section{Supplemental Information \\ Videos}

Video 1, Media Player. http://mfile.akamai.com/21490/wmv/ digitalwbc.download.akamai.com/21492/wm.digitalsource-naregional/jns14-2088_video_1.asx.

Video 1, Quicktime. http://mfile.akamai.com/21488/mov/ digitalwbc.download.akamai.com/21492/qt.digitalsource-global/ jns14-2088_video_1.mov.

Video 2, Media Player. http://mfile.akamai.com/21490/wmv/ digitalwbc.download akamai.com/21492/wm.digitalsource-naregional/jns14-2088_video_2.asx.

Video 2, Quicktime. http://mfile.akamai.com/21488/mov/ digitalwbc.download.akamai.com/21492/qt.digitalsource-global/ jns14-2088_video_2.mov.

\section{Correspondence}

Aaron A. Cohen-Gadol, Goodman Campbell Brain and Spine, Indiana University Department of Neurosurgery, 355 W. 16th St., Ste. 5100, Indianapolis, IN 46202. email: acohenmd@ gmail.com. 